Acta Hispanica (2020) Supplementum II: 747-757

\title{
MARIÁTEGUI Y CHAPLIN, VANGUARDISMO CINEMATOGRÁFICO E INDUSTRIA CULTURAL
}

\author{
JAIME VILLARREAL \\ Benemérita Universidad Autónoma de Puebla
}

\begin{abstract}
Resumen: Aunque el ensayista peruano José Carlos Mariátegui (1894-1930) es mejor conocido por ser el primero y más original pensador marxista latinoamericano, en este artículo me propongo explorar una de las facetas de su pensamiento como precursora de la línea que observó el carácter cultural del capitalismo y, por necesidad, conjuntó la indagación económica y sociológica con la crítica filosófica para entender la profundidad de los fenómenos de la cultura popular y masiva de la primera mitad del siglo XX. En especial me interesa destacar la compatibilidad y la discrepancia de ideas con el concepto de industria cultural, que sirvió a Theodor Adorno y Max Horkheimer para caracterizar la lógica mercantilista y reproductora del sistema capitalista representada en las producciones cinematográficas hollywoodenses. Con un breve repaso por las líneas principales del pensamiento estético de Mariátegui, indago aquí tanto en esa perspectiva precursora como en las razones por las cuales el Amauta consideró a Chaplin uno de los grandes artistas de su tiempo. Palabras clave: José Carlos Mariátegui, industria cultural, vanguardias, ensayo latinoamericano, Charles Chaplin.
\end{abstract}

Abstract: Although the Peruvian essayist José Carlos Mariátegui (1894-1930) is best known for being the first and most original Latin American Marxist thinker, in this article I propose to explore one of the facets of his thinking as a precursor to the line that observed the cultural character of capitalism and, by necessity, combined economic and sociological inquiry with philosophical criticism to understand the depth of the popular and mass cultural phenomena of the first half of the twentieth century. I am especially interested in highlighting the compatibility and discrepancy of ideas with the concept of culture industry, which served Theodor Adorno and Max Horkheimer to characterize the mercantilist and reproductive logic of the capitalist system represented in Hollywood film productions. With a brief review of the main lines of Mariategui's aesthetic thinking, I inquire here both in that precursor perspective and in the reasons why the Amauta considered Chaplin one of the greatest artists of his time.

Keywords: José Carlos Mariátegui, Culture Industry, Avant-garde, Latin American Essay, Charles Chaplin.

\section{Introducción}

José Carlos Mariátegui no limitó su indagación al arte literario, más a su alcance por la circulación de los textos impresos, también encontró una "fuerza suprarreal" en el Charlot de Charles Chaplin (1889-1977), específicamente en la película The Gold Rush (La quimera del oro, 1925): "Artística, espiritualmente, excede, hoy, al teatro de Pirandello y a la novela 
de Proust y de Joyce"1. Y, más allá, el Amauta entendió el cine como una forma de acceder, efectiva y sintéticamente, por la vía tecnológica a la compleja realidad de la sociedad en que le tocó vivir. No por casualidad, en su primer libro de ensayos, La escena contemporánea (1925), afirmó: "el mejor método para explicar y traducir nuestro tiempo es, tal vez, un método un poco periodístico y un poco cinematográfico" (1959: 11). De esta manera definía la intención de su escritura ensayística imaginativa y fragmentaria.

En esos pioneros escarceos del peruano sobre la experimentación artística en el cine silente, además de en sus ensayos acerca del cambio en el papel de los creadores modernos, politizados y opositores de la figura romántica del creador artepurista ("La torre de marfil", 1924 o "Aspectos viejos y nuevos del futurismo", 1921), se cifra una argumentación fundamental de la perspectiva que fusiona humanidades y ciencias sociales para adecuarse a la complejidad de la investigación estética moderna.

\section{Contra la sustitución de la política por la estética}

Antes incluso de su regreso de Europa, donde más bien se dedicó a seguir el debate político europeo, el ensayista dio muestra de la sofisticación de sus concepciones estéticopolíticas. En "Aspectos viejos y nuevos del futurismo"2, artículo vital para su reflexión estética, reseña la reaparición pública en la posguerra de Filippo Tommaso Marinetti (1876-1944), fundador del movimiento pionero de vanguardia surgido en Italia en 1909. Entre los apuntes acerca del contexto que primaba en ese retorno futurista, Mariátegui destaca el surgimiento de la pluralidad de movimientos de vanguardia (cubismo, expresionismo, dadaísmo) y la paulatina aceptación de aquellas obras rupturistas en los circuitos del mercado del arte. Sobre todo, llama la atención del comentarista lo que consideró "una de las desviaciones del movimiento": la instauración de un programa político futurista.

En este ensayo Mariátegui se alejó del romántico y frívolo culto a la personalidad, su crítica se ensanchó hasta situar la obra y los discursos artísticos en su contexto sociopolítico. No expuso entonces la incompatibilidad de la estética y la política: "El grande artista no fue nunca apolítico" (2006a: 37). Más bien evidenció, como lo haría años después Walter Benjamin ${ }^{3}$, la falaz sustitución de la política por la estética llevada a cabo en aquel cónclave vanguardista:

No hay, pues, nada que reprochar a Marinetti por haber pensado que el artista debía tener un ideal político. Pero sí hay que reírse de él por haber supuesto que un comité de artistas podía improvisar de sobremesa una doctrina política. La ideología política de un artista no puede salir de las asambleas de estetas. Tiene que ser una

\footnotetext{
1 "Esquema de una explicación de Chaplin", Variedades, 6 y 13 de octubre de 1928.

2 Publicado en El Tiempo, 3 de agosto de 1921.

3 "La obra de arte en la época de su reproductibilidad técnica" (1936).
} 
Jaime Villarreal

ideología plena de vida, de emoción, de humanidad y de verdad. No una concepción artificial, literaria y falsa (2006a: 37).

\section{Contra el artepurismo}

Por esas sendas había reflexionado Mariátegui el problema de la politización de los intelectuales, y, ya en 1924, en su ensayo "La torre de marfil"", retomó aquella reflexión para definir la que fue en adelante su más firme posición en contra del creador individualista y apolítico. En su ensayo retoma, sin mencionarlo, una apreciación atribuida al crítico francés Charles Augustin de Sainte-Beuve (1804-1869), quien caracterizó la costumbre solitaria del romántico Alfred de Vigny (1797-1863) como una reclusión en su torre de marfil, acuñando así una de las etiquetas típicas de las tendencias artepuristas a partir del romanticismo.

En este mismo artículo ejerce una idea dialéctica, presente en ensayos previos ("Postimpresionismo y cubismo", de 1924), de la historia cultural dinamizada por la oposición entre una época clásica y otra romántica. Entonces, el Amauta entiende tanto el romanticismo como el clasicismo como componentes de la historia de la cultura moderna. Por supuesto, consideró su propia época como convulsa, revolucionaria y, en ese sentido, romántica. De esa manera, calificó como pasadistas a aquellos nostálgicos, conservadores no dispuestos a adaptarse a una etapa de cambios radicales sociales y políticos: "En una tierra de gente melancólica, negativa y pasadista, es posible que la Torre de Marfil tenga todavía algunos amadores. Es posible que a algunos artistas e intelectuales les parezca aún un retiro elegante" (2006c: 72). El pasadismo peruano, lo había expuesto en un ensayo publicado en ese mismo año ${ }^{5}$, era aristocrático, nostálgico de la Colonia, del virreinato y no del mundo incaico: "Esa edad es demasiado autóctona, demasiado nacional, demasiado indígena para emocionar a los lánguidos criollos de la república" (2006d: 68). De esta manera iba ya ligando su vanguardismo marxista con su indigenismo.

A diferencia de países convulsos como México, en la segunda mitad de los años veinte en el Perú el torremarfilismo, en el que en buena medida militó el mismo Mariátegui junto a los Colónidas durante la década anterior ${ }^{6}$, se convirtió en uno de los vicios a combatir y superar en el terreno intelectual. En cambio, algunos artistas peruanos sostuvieron una "Torre" que en Europa: "Vetusta, deshabitada, pasada de moda, albergó hasta la guerra a algunos linfáticos artistas. Pero la marejada bélica la trajo a tierra. La Torre de Marfil cayó sin estruendo y sin drama. Y hoy, malgrado la crisis de alojamiento, nadie se propone reconstruirla" (2006d: 72).

\footnotetext{
${ }^{4}$ Publicado en Mundial, 7 de noviembre de 1924.

${ }^{5}$ En "Pasadismo y futurismo" (Mundial, 31 de octubre de 1924), destacó las tendencias melancólica y pasadista de las letras y la cultura peruanas.

${ }^{6}$ Grupo literario de ruptura, integrado alrededor de la efímera revista del mismo nombre fundada y producida en 1916 por Abraham Valdelomar.
} 
Mariátegui y Chaplin, vanguardismo cinematográfico e industria cultural

En términos de Lakoff y Johnson (1986), Mariátegui busca el origen de la metafórica torre producida por el decadentismo de entre siglos hasta situarla históricamente ("Tiempos quietos, normales, burocráticos, pudieron tolerarla"), como tipo concreto de edificio arquitectónico producido sobre todo en las sociedades del Medievo. Uno de sus recursos reflexivos era la construcción de una imagen ilustrativa de la abstracción sobre la que versaran sus argumentos. En un ensayo sobre Rainer Maria Rilke, anota: "todas las teorías modernas se caracterizan por la posibilidad de poder expresarse gráficamente" (2012b: 43-44).

Como bien lo describió Walter Benjamin una década después7 , el capitalismo le echó en cara al artista romántico y artepurista su condición de productor. Aquellos movimientos regresivos, romanticismo y decadentismo, tomaron el símbolo aislacionista para significar el rechazo al cambio radical del modo de producción y del racionalismo ilustrado:

El torremarfilismo formó parte de esa reacción romántica de muchos artistas del siglo pasado contra la democracia capitalista y burguesa. Los artistas se veían tratados desdeñosamente por el capital y la burguesía. Se apoderaba, por ende, de sus espíritus una imprecisa nostalgia de los tiempos pretéritos. Recordaban que bajo la aristocracia y la Iglesia, su suerte había sido mejor. El materialismo de una civilización que cotizaba una obra de arte como mercadería los irritaba. Les parecía horrible que la obra de arte necesitase réclame, empresarios, etc., ni más ni menos que una manufactura, para conseguir precio, comprador y mercado. A este estado de ánimo corresponde una literatura saturada de rencor y de desprecio contra la burguesía. Los burgueses eran atacados no como ahora, desde puntos de vista revolucionarios, sino desde puntos de vista reaccionarios (2006d: 73$)$.

Además de la clara consideración que encuadra las actividades artísticas en la lógica de la economía de mercado, uno de los presupuestos de la industria cultural, con ese sentido concreto, materialista, Mariátegui diferencia los espacios y edificaciones de las épocas modernas, menos autoritarias, acorazadas, amuralladas, aristocráticas o dominadas por el clero. Las sociedades democráticas e inclinadas por la cultura colectiva generaron otro tipo de edificios y áreas para el ciudadano: el ágora griega, la mole romana y el rascacielos neoyorkino convocan la colectividad: "Las torres de esta civilización son utilitarias e industriales. Los rascacielos de Nueva York no son torres sino moles. No albergan solitaria y solariegamente a un campanero o a un hidalgo. Son la colmena de una muchedumbre trabajadora. El rascacielos, sobre todo, es democrático en tanto que la torre es aristocrática" (2006d: 74). Este manifiesto en contra del artepurismo cimentó las reflexiones posteriores del Amauta.

7 “El autor como productor" (1934). 
Jaime Villarreal

\section{Precursor en la indagación de la industria cultural}

En su volumen Dialéctica de la ilustración (1944), publicado originalmente con el título Fragmentos filosóficos, Adorno y Horkheimer subtitulan uno de sus apartados más célebres "La industria cultural. Ilustración como engaño de masas". Los autores exiliados afirman desde la California en que se cimentaba la producción audiovisual estadounidense:

La cultura ha contribuido a domar y controlar los instintos, tanto los revolucionarios como los bárbaros. La cultura industrializada hace aún algo más. Ella enseña e inculca la condición que es preciso observar para poder tolerar de algún modo esta vida despiadada (1998: 197).

En este sentido, acerca de la insistencia con la cual el cine hollywoodense, y las ficciones en general consumidas en la cultura de masas, concluye en finales felices útiles para fomentar la anuencia y la reproducción del sistema capitalista, acotan los alemanes:

Como toda opereta húngaro-vienesa que se preciara debía tener en su segundo acto un final trágico, que no dejaba al tercero más que la aclaración de los malentendidos, así la industria cultural asigna a lo trágico su lugar preciso en la rutina. Ya la notoria existencia de la receta basta para calmar el temor de que lo trágico escape al control. La descripción de la fórmula dramática por parte de aquella ama de casa: "meterse en los líos y salir a flote", define la entera cultura de masas, desde el women serial más idiota hasta la obra cumbre (1998: 197).

Por otro lado, y en un sentido más contemporáneo, acerca del giro que adquirió el concepto industria cultural después de su acuñación por los frankfurtianos, en su introducción al Diccionario de estudios culturales latinoamericanos, Szurmuk y McKee Irwin señalan:

En contraposición al enfoque en obras de arte de la cultura letrada, los estudios culturales se han enfocado en formas de cultura "baja", popular y masiva. Heredan de la diáspora intelectual judeo-alemana exiliada del nazismo, la preocupación por el poder de la industria cultural y el interés por analizar nuevos modos de producción cultural, muchas veces con el signo cambiado: si para la escuela de Frankfurt la industria cultural significaba el final de la originalidad en el arte y la creación de una sociedad masificada sin libertad individual, donde el arte era una mercancía más (Adorno y Horkheimer), los estudios culturales buscarán los espacios de resistencia dentro de la cultura popular y de masas (2009: 14). 
En este cambio de perspectiva coinciden no sólo la entrada dedicada al concepto de "Industria cultural" en el mismo Diccionario, firmada por Victoria Ruétalo, sino también múltiples estudiosos contemporáneos. Entre ellos, destaca Jesús Martín Barbero, autor de un texto clásico del estudio de la comunicación en Latinoamérica, el ensayo De los medios a las mediaciones (1987). En el apartado "Industria cultural: capitalismo y legitimación", que incluye el subtítulo "Benjamin vs. Adorno o el debate de fondo", Martín Barbero destaca la relevancia directa que el pensamiento de los frankfurtianos tuvo para la crítica latinoamericana, en especial el de Adorno, y, a la vez, subraya lo inapropiado que resultaron aquellos esquemas para reflexionar sobre América Latina: "fuimos descubriendo todo lo que el pensamiento de Frankfurt nos impedía pensar a nosotros, todo lo que de nuestra realidad social y cultural no cabía ni en su sistematización ni en su dialéctica" (1991: 49).

La diversa valoración de la obra de Chaplin, sobre la cual reflexionan Mariátegui, Adorno, Horkheimer y Martín Barbero, se vuelve una clave para entender la calidad de precursor que el Amauta representa. Por un lado, para Adorno y Horkheimer: "La diversión es la prolongación del trabajo bajo el capitalismo tardío" (1998: 181). Y, en ese sentido, el ocio tiene una función adaptativa al trabajo. Al espectador se le niega, según expresan los alemanes, la posibilidad de pensar: "no debe necesitar de ningún pensamiento propio" (1998: 181). Esta condición se ve reflejada en la tendencia al absurdo o sinsentido "que tuvo parte legítima en el arte popular, la farsa y la payasada hasta Chaplin y los hermanos Marx". Es decir, incluso Chaplin cabe en la misma bolsa reproductora del sistema y del poder del capital.

Esta visión totalizante es criticada por Martín Barbero y calificada como un argumento abusivo que niega toda posibilidad de resistencia: "Pero esa afirmación de la 'unidad' se torna teóricamente- abusiva y políticamente peligrosa cuando de ella se concluye la totalización de la que se infiere que del film más ramplón a los de Chaplin o Welles ‘todos los films dicen lo mismo', pues aquello de lo que hablan 'no es más que el triunfo del capital invertido"' (1991: 50). Por las consecuencias radicales de afirmaciones como la anterior, Martín Barbero tacha de aristocratismo al pensamiento de Adorno que "se niega a aceptar la existencia de una pluralidad de experiencias estéticas, una pluralidad de los modos de hacer y usar socialmente el arte" (1991: 54). En esa crítica le asiste el contraste con la obra de Benjamin, quien pone el acento en la democratización, en el cambio perceptual implícito en la tecnología de reproducción mecánica de las imágenes que acerca lo lejano y lo desacraliza o lo desauratiza. Así puede concluirse de una lectura que le otorgue su justo lugar al ensayo de 1936, "La obra de arte en la época de su reproductibilidad técnica" (Benjamin, 1989).

Mariátegui, incluso antes que Benjamin, es precursor de la búsqueda de espacios de resistencia en las expresiones de los llamados medios masivos. Así, para el caso de Chaplin, se pregunta cómo un artista proveniente de una familia de clowns ingleses se ha visto atraído por Hollywood: 
Jaime Villarreal

Chaplin proviene, según un dato en que insiste siempre su biografía, de una familia de clowns, de artistas de circo. En todo caso, él mismo ha sido clown en su juventud. ¿Qué fuerza ha podido sustraerlo a este arte, tan consonante con su ánima de bohemio? La atracción del cinema, de Hollywood, no me parece la única y ni siquiera la más decisiva. Tengo el gusto de las explicaciones históricas, económicas y políticas y, aún en este caso, creo posible intentar una, quizá más seria que humorística (2006b: 126).

Es interesante que el Amauta se proponga una explicación contextual amplia para entender la atracción-repulsión entre Chaplin y Hollywood, la resistencia que el director inglés ejercía en el seno mismo de la producción cinematográfica estadounidense. En esa vía interpretativa vasta, se encuentra la clave para leer su ensayística como precedente de la perspectiva culturalista que tiene como una de sus vertientes a la industria cultural.

\section{El cine en el marco del pensamiento estético mariateguiano}

¿Cómo entendía el peruano el fenómeno cinematográfico en su más revolucionaria expresión estética? En "Arte, revolución y decadencia”8 (1926), Mariátegui cristaliza una tesis esbozada un par de años antes ("Poetas nuevos y poesía vieja", 1924) acerca de las características del arte nuevo:

\footnotetext{
No podemos aceptar como nuevo un arte que no nos trae sino una nueva técnica. Eso sería recrearse en el más falaz de los espejismos actuales. Ninguna estética puede rebajar el trabajo artístico a una cuestión de técnica. La técnica nueva debe corresponder a un espíritu nuevo también. Si no, lo único que cambia es el paramento, el decorado. Y una revolución artística no se contenta de conquistas formales (2012d: 148).
}

Como queda claro, a diferencia de Adorno y Horkheimer, quienes no veían las posibilidades subversivas en esta nueva forma de expresión, la posición del Amauta no se encuentra ni en la tecnofilia ni en la tecnofobia. Y, si bien no fue un teórico del cine, el peruano se coloca más cerca de lo que se conoce ideológicamente como montaje soberano, representado por teóricos como Eisenstein, postura contraria al cine de la transparencia de Bazin (Aumont et al, 2005: 71). Esto es coherente con las ideas del Amauta que, en su ensayo de 1926, "La realidad y la ficción", había declarado acerca de la literatura: "La experiencia realista no nos ha servido sino para demostrarnos que sólo podemos encontrar la realidad por los caminos de la fantasía” (Mariátegui, 1991: 390).

\footnotetext{
${ }^{8}$ Publicado en Amauta, 3 de noviembre de 1926.
} 
Mariátegui y Chaplin, vanguardismo cinematográfico e industria cultural

\section{Chaplin y el surrealismo}

Como algunos otros intelectuales de la época, el Amauta fue gran admirador de Chaplin y un entusiasta del movimiento surrealista. Muy probablemente, intensificó su interés por el inglés alentado por la admiración que le dedicaban los miembros del grupo surrealista, incluso antes de formar parte del movimiento de vanguardia. En especial Philippe Soupault y Louis Aragon (aunque también Breton, Desnos, Vaché, etc.) escribieron poemas y prosas dedicados a Chaplin y a su personaje, Charlot.

Como ejemplo, podemos mencionar el caso de Louis Aragon, quien publicó poemas y prosas críticas acerca de Chaplin en el semanario Le Film, dirigido por Louis Delluc: un poema inspirado en los cortometrajes de Chaplin, "Charlot sentimental" (18 de marzo de 1918), o el ensayo titulado "Du decor" (Sobre el decorado, 1918). En este último pide a los artistas de su tiempo inspirarse en el trabajo del director que se atrevió a utilizar los objetos cotidianos en su propuesta artística.

Ya como colectivo, miembros del grupo surrealista (32 autores varones) publicaron un manifiesto en apoyo al artista inglés con motivo de su publicitado juicio de separación con su exesposa, la actriz Lita Grey, madre de dos de sus hijos9. El breve matrimonio, que duró entre 1924 y 1927, transcurrió en medio de muchos problemas, mientras Chaplin filmaba precisamente The Gold Rush. Ese manifiesto respondía a un libro titulado The Complaint of Lita (1927), que daba a conocer la versión de Grey, su segunda esposa, unos 20 años menor que el cineasta, acerca de los supuestos maltratos y vejaciones que habría sufrido a manos del inglés. Los surrealistas consideraron tanto el libro como el juicio representativos del puritanismo e hipocresía imperantes en los Estados Unidos de la época. En la descalificación de la demandante y el apoyo incondicional al acusado por parte de los firmantes, de hecho, queda manifiesta una postura moral androcéntrica propia de aquellos tiempos. Además, el texto describe a Grey como una mujer mojigata movida por su interés en el dinero de Chaplin, mientras el cineasta es visto como un artista no convencional partidario del amor libre. No es casual que el amor, leitmotiv surrealista, adquiera relevancia en el comentario crítico de Mariátegui acerca de The Gold Rush.

\section{La imagen muda democrática y la fuerza suprarreal}

Tanto Chaplin como el Amauta consideraron al cine silente y a la pantomima ejercida en él como expresiones democratizadoras, no sujetas a una lengua nacional específica. En "Esquema de una explicación de Chaplin", Mariátegui destaca el estilo depurado de The Gold Rush centrada en las imágenes: "Chaplin ha logrado, en esta obra, expresarse sólo en imágenes. Los letreros están reducidos al mínimum. Y podría habérseles suprimido totalmente, sin que el espectador se hubiese explicado menos la comedia" (2006b: 126).

9 "Hands off Love", La révolution surréaliste 9-10, octubre de 1927. 
Así, la pantomima se encuentra en la base de aquel arte de imágenes: "La pantomima es el origen del arte cinematográfico, mudo por excelencia, a pesar del empeño de hacerlo hablar" (2006b: 126). Bien se sabe que para 1928, año en que se publicó su ensayo, se habían intensificado los experimentos para sonorizar el cine.

Por otro lado, el mismo Chaplin rechazó la sonorización del cine que cundió en la década de los treinta. Para su campaña de promoción de City Lights (1931), utilizó un texto titulado "A Rejection of the Talkies" (En rechazo de las películas habladas, 1931): "¿Por qué continué haciendo películas sin diálogos? La imagen muda, antes que otra cosa, es un medio universal de expresión. Las imágenes habladas tienen necesariamente un campo limitado, se mantienen en la lengua particular de las razas particulares" (2014: 568) ${ }^{10}$. Ahí mismo, destacó el papel primordial que la pantomima y la carencia de diálogo audible tenían para potenciar al cine como una expresión universal:

La imagen muda, ante todo, es un medio universal de expresión. Las imágenes que hablan tienen necesariamente un campo limitado, se mantienen en la lengua particular de las razas particulares. Confío que el futuro verá un retorno de interés de las producciones que no hablan porque hay una demanda constante de un medio que es universal en su utilidad (2014: 568).

Pero la resistencia de Chaplin en Hollywood no se redujo al rechazo de la tecnología de sonorización. Se trata más bien de una postura política crítica contraria a la sociedad capitalista que enmarcaba a esa industria cinematográfica. Mariátegui explica esa postura, esa tensión generadora entre Chaplin y el ámbito hollywoodense, aludiendo a uno de los grandes recursos del realizador, su alter ego, Charlot:

Para llegar a la más honda y desnuda humanidad, al más puro y callado drama, Chaplin necesita absolutamente la pobreza y el hambre de Charlot, la bohemia de Charlot, el romanticismo y la insolvencia de Charlot. Es difícil definir exactamente al bohemio. Navarro Monzó -para quien San Francisco de Asís, Diógenes y el propio Jesús serían la sublimación de esta estirpe espiritual dice que el bohemio es la antítesis del burgués. Charlot es antiburgués por excelencia. Está siempre listo para la aventura, para el cambio, para la partida. Nadie lo concibe en posesión de una libreta de ahorros. Es un pequeño Don Quijote, un juglar de Dios, humorista y andariego (2006b: 123) ${ }^{11}$.

\footnotetext{
${ }^{10}$ Las traducciones son del autor.

${ }^{11}$ Hay que señalar la admiración de Mariátegui por Miguel de Unamuno, quien argumentó sobre el quijotismo como una aportación hispánica a la filosofía occidental, a partir de un artículo, "Quijotismo", publicado en 1895 y hasta sus últimas publicaciones.
} 
Mariátegui y Chaplin, vanguardismo cinematográfico e industria cultural

Este alter ego bohemio, artista desposeído, libre y poco convencional, representa valores románticos apenas aceptables para el capitalismo tecnificado, cuya "conquista del oro, el gold rush ha sido el capítulo romántico, la fase bohemia de la epopeya capitalista" (2006b: 122). Como el Quijote, Charlot enamorado se aventura en una nueva búsqueda del oro. Y, volviendo al contraste con las ideas de Adorno y Horkheimer, el final feliz de The Gold Rush no obsta para que el Amauta considere a la película, a la vez, una gran obra de arte y una experiencia disfrutable para la generalidad: "el arte de Chaplin es gustado, con la misma fruición, por doctos y analfabetos, por literatos y por boxeadores" (2006b: 122). Ese desenlace hoy típico del cine hollywoodense, en que el héroe "se queda con el oro y con la chica", es necesario en dicha obra por ser propiciado por la pasión amorosa tan defendida por los surrealistas.

El final de The Gold Rush -que algunos hallan vulgar, porque preferirían que Charlot regresara a su bohemia descamisada- es absolutamente justo y preciso. No obedece mínimamente a razones de técnica yanqui. Toda la obra está insuperablemente construida. El elemento sentimental, erótico, interviene en su desarrollo como medida matemática, con rigurosa necesidad artística y biológica (2006b: 123-124).

Por último, habría que centrarse en ese choque, conflicto y resistencia generadora del arte de Chaplin en el hegemónico campo cultural norteamericano:

Pero Estados Unidos no se ha asimilado espiritualmente a Chaplin. La tragedia de Chaplin, el humorismo de Chaplin, obtienen su intensidad de un íntimo conflicto entre el artista y Norte América. La salud, la energía, el élan de Norte América retienen y excitan al artista; pero su puerilidad burguesa, su prosaísmo arribista, repugnan al bohemio, romántico en el fondo. Norte América, a su vez, no ama a Chaplin. Los gerentes de Hollywood, como bien se sabe, lo estiman subversivo, antagónico. Norte América siente que en Chaplin existe algo que le escapa. Chaplin estará siempre sindicado de bolchevismo, entre los neo-cuáqueros de la finanza y la industria yanquis (2006b: 127-128).

\section{Referencias bibliográficas}

Adorno, Theodor - Max Horkheimer (1998). Dialéctica de la ilustración. Fragmentos filosóficos. Tercera edición. Madrid: Trotta.

Alexandre, Maxime; Aragon, Louis et. al. (2014). Hands off Love. En: MacKenzie, Scott (ed.). Film Manifestos and Global Cinema Cultures. A Critical Anthology. California: University of California Press. 330-336. 
Jaime Villarreal

Aumont, Jacques et. al. (2005). Estética del cine. Espacio fülmico, montaje, narración, lenguaje. Buenos Aires: Paidós.

Benjamin, Walter (1989). La obra de arte en la época de su reproductibilidad técnica. Discursos interrumpidos I. Filosofía del arte y de la historia. Traducción de Jesús Aguirre. Buenos Aires: Taurus. 15-60.

Chaplin, Charlie (2014). A Rejection of the Talkies. En: MacKenzie, Scott (ed.). Film Manifestos and Global Cinema Cultures. A Critical Anthology. California: University of California Press. 568-569.

Lakoff, George - Mark Johnson (1986). Metáforas de la vida cotidiana. Madrid: Cátedra.

Mariátegui, José Carlos (2012). Arte, revolución y decadencia. Ensayos literarios. Sobre Joyce, Breton y las vanguardias europeas. Buenos Aires: Mardulce. 147-151.

Mariátegui, José Carlos (2006a). Aspectos viejos y nuevos del futurismo. Literatura y estética. Selección de Mirla Alcibíades. Caracas: Biblioteca Ayacucho. 35-38.

Mariátegui, José Carlos (2006b). Esquema de una explicación de Chaplin. Literatura y estética. Selección de Mirla Alcibíades. Caracas: Biblioteca Ayacucho. 121-128.

Mariátegui, José Carlos (2006c). La torre de marfil. Literatura y estética. Selección de Mirla Alcibíades. Caracas: Biblioteca Ayacucho. 72-76.

Mariátegui, José Carlos (2006d). Pasadismo y futurismo. Literatura y estética. Selección de Mirla Alcibíades. Caracas: Biblioteca Ayacucho. 67-71.

Mariátegui, José Carlos (1991). El balance del suprarrealismo. Textos básicos. Selección de Aníbal Quijano. México: Fondo de Cultura Económica. 392-396.

Mariátegui, José Carlos (1984). Correspondencia (1915-1930). Tomo I. Lima: Amauta.

Mariátegui, José Carlos (1959). La escena contemporánea. Lima: Biblioteca Amauta.

Martín Barbero, Jesús (1991). De los medios a las mediaciones. Comunicación, cultura y hegemonía. México: Gustavo Gili.

Szurmuk, Mónica - McKee Irwin, Robert (2009). Diccionario de estudios culturales latinoamericanos. México: Siglo XXI. 